\title{
Turismo e Eventos: Instrumento de Promoção e Estratégia de Marketing
}

\author{
Janaina Britto Carneiro \\ Nena Dantas Fontes ${ }^{2}$
}

RESUMO: Enfoca a importância da análise dos eventos como instrumento de promoção e estratégia de marketing, ressaltando toda a sua potencialidade. A organização de eventos requer planejamento detalhado de marketing, no qual a divulgação e a promoção têm papéis relevantes. No turismo de eventos o procedimento é semelhante, evidenciando sua responsabilidade no gerenciamento da recepção do público-alvo de eventos em geral.

PALAVRAS-CHAVE: Turismo e eventos; eventos; estratégia; promoção; marketing.

ABSTRACT: The article focuses on the importance of analysing events as a promotion and marketing strategy, stressing their potentiality. In order to plan the organization of events is necessary to elaborate a market programme and formulate rules in which the promotion and the events must be strategically placed. Besides this, the tourism of events is responsible for managing the reception activity for the target market which is the consumer of all the events.

KEY WORDS: Tourism and events; events; strategy; promotion; marketing.

1. Bacharel em Turismo pela Faculdade de Turismo do Morumbi e em Comunicaçōes e Artes pela Universidade Mackenzie. Mestranda em Turismo e Lazer pela ECA-USP. Coordenadora do curso de graduação em Turismo da Universidade de Santo Amaro - UNISA. Consultora de Turismo e Eventos.

End. para corresp.: Av. Jacutinga, 120 - apto. 21 - 04515-030 - São Paulo - SP - Brasil. Fax: (011) 542-7419.

2. Bacharel em Turismo pela Faculdade de Turismo do Morumbi, com pós-graduação em Marketing e Eventos pela Escuela de Turismo de Baleares Estudio General Luliano em Palma de Maiorca - Espanha. Consultora na área de Turismo e Eventos. Diretora de Marketing da Dantas Britto Projetos em Turismo e Eventos Ltda. 


\section{Introdução}

O evento, tratado exclusivamente como linguagem única de Comunicação para a área de vendas, embora possuindo características que os diferem uns dos outros conforme sua abrangência disciplinar e atuação, não obedece, por vezes, à dinâmica necessária da promoção, à assimilação do seu objeto eà divulgação de seus objetivos, como finalidade de estratégia de marketing.

As atividades de vendas propriamente ditas são partes integrantes ao processo de marketing, que tem inserido em seu contexto não só as trocas de produtos e valores, como também a identificação e a consideração das necessidades do consumidor ou público-alvo. Este, não mais tratado de forma impessoal, mas corretamente detectado e identificado.

O evento, considerado como estratégia de promoção dentro do marketing, tem analisadas a satisfação das necessidades dos clientes e o processo social de demanda de desejos, o planejamento de oferta deprodutos e o gerenciamento de idéias e valores adequados ao mercado. É a finalização de todo o planejamento estratégico estrutural funcional e de marketing quepropõem a concretizaçãoem si dainteração mercadológica ou instiga e apresenta uma inovação e discussão inédita.

\section{Eventos e o Processo de Marketing}

Eventos são todos os acontecimentos previamente planejados, organizados e coordenados de forma a contemplar o maior número de pessoas em um mesmo espaço físico e temporal, com inforınações, medidas e projetos sobre uma idéia, ação ou produto, apresentando os diagnósticos de resultados e os meios mais eficazes para se atingir determinado objetivo. Pela própria definição, o evento vem se mostrando cada vez mais requisitado e, pela sua concepção estrutural e funcional, pressupõe ações cada vez mais complexas.

Por outro lado, o marketing vem sendo desenvolvido a partir de um padrão de vida do indivíduo; por este é afetado e simultaneamente afeta a sociedade. É, então , uma atividade direcionada à satisfação de necessidades e desejos através do inventário destas, criando soluções e patrocinando a interação entre as partes.

$\mathrm{O}$ marketing requer o planejamento estratégico do empreendedor (aqui entendido como a entidade ou o empresário interessado no assunto), definindo seu papel e auxiliando, portanto, na interação e formalização de seus métodos funcionais.

\section{Planejamento Estratégico}

O empreendedor, motivado e decidido, estuda o ambiente de marketing em busca de reais oportunidades. Tal ambiente é composto de elementos humanos e materiais que afetam sua capacidade de interação com o mercado-alvo de forma eficaz.

O ambiente de marketing é composto da estrutura administrativa, dos canais de marketing, dos mercados consumidor, produtor, revendedor, governamental e internacional, dos mercados concorrentes e de todos os públicos em que tenha interessè real ou potencial.

Uma vez definido tal ambiente, também denominado microrregião, o empreendedor passa à análise do macroambiente ou macrorregião de marketing, defínido como o ambiente demográfico, econômico, natural, tecnológico, político e cultural. Portanto, estarão definidas as reais oportunidades mediante análise de sua estrutura administrativa, seus fornecedores e revendedores, seus agentes financeiros, sua relação com a mídia, a comunidade local e público, faixa etária da população envolvida, diversidade étnica, as mudanças na renda real e padrões dos consumidores, o regrado abastecimento das matérias-primas pertinentes ao seu negócio, custos operacionais e energéticos, os níveis de poluição, intervenção governamental na administração dos recursos naturais, as rápidas mudanças tecnológicas, oportunidades'de renovação, orçamentos, legislação governamental e participação dos grupos de interesses, tendências culturais e busca de valores mais significativos.

O empreendedor, munido dessas informações, parte para a pesquisa propriamente dita que se inicia e termina no usuário. Tal pesquisa vai identificar o mercado, os sistemas de inforınações, o mercado consumidor e seu comportamento, proceder a mensuração e previsão da demanda, definir seu público-alvo, elaborar o planejamento de seus produtos e estratégias de preços, definir seus canais de distribuição e controle, analisar a concorrência, traçar a estratégia de marketing competitivo e finalmente elaborar seu Programa de Marketing que determina a propaganda, promoção e divulgação de seus produtos e serviços.

Dessa forma o Programa deMarketing estará apto e atendendo aos produtos, entidades "vendáveis" - serviços, organizações, pessoas, idéias e lugares (os empreendedores).

À medida que a economia mundial avança em direção à economia de serviços, os profissionais de marketing (e de eventos) necessitam conhecer profundamente essas novas tendências que atingem, principalmente, o mercado das Comunicações.

Novas definições são integradas ao Planejamento Global de Marketing:

- marketing de serviços: considerando-se que serviços são atividades ou benefícios oferecidos de uma parte à outra e essencialmente intangiveis, não resultam em posse de bens. Os serviços são intangiveis, inseparáveis, variáveise pereciveis características únicas que apresentam problemas e solicitam estratégias especiais. O empreendedor deve traçar metas para tornar tais serviços tangíveis aumentando a produtividade de seus fornecedores, padronizando sua qualidade, melhorando a capacidade de ofertas, e criando diferenciações competitivas com o auxílio do profissional de marketing (e de eventos). O turismo faz uso constante das premissas do marketing de serviços; 
- marketing de organizações: estas também podem ser "vendidas". E o chamado marketing institucional constituido para criar, manter e alterar comportamentos e atitudes do público-alvo frente à determinada organização. Avaliada e analisada a imagem desta, desenvolve-se o plano de marketing para gerar a imagem almejada e adcquada;

- marketing de pessoas: com o mesmo peso do marketing institucional, o marketing de pessoas atua principalmente na criação de uma imagem adequada. Tem sua atuação mais comum entre as pessoas consideradas celebridades e candidatos politicos. Abrangendo todas as técnicas de comunicação, irá nortear o processo com vistas a suprir as necessidades de um público específico, angariando a aprovação da sociedade, construindo uma imagem pessoal sólida que transmita confiabilidade;

- marketing de locais: o marketing de locais envolve atividades que alteram o comportamento em relaçãoa lugares. São suas estratégias que delimitam as ações de promoção de destinosconsiderados turísticos, juntamente com os procedimentos do marketing de produtos e serviços;

- marketing de idéias: também chamado de marketing social, define as necessidades de mudanças e propõe novo pensamento a respeito de uma causa ou assunto, solicitando programas que aumentam a credibilidade dessa nova idéia. Desenvolvendo canais apropriados na distribuição de idéias, o marketing social tem sido aplicado a programas de planejamento familiar, campanhas antifumo programas de proteção ambiental e desenvolvimento sustentável, entre outras questões públicas. Como se pode perceber, cada ocasiãonorteia um planejamento de marketing adequado às suas feições e propósitos, e reciprocamente por este é norteado, sempre alicerçado nas diretrizes do marketing convencional.

\section{Evento como Estratégia de Marketing}

Como qualquer acontecimento social programado para interagir dentro dos mais variados mercados, o evento é uma atividade previamente planejada dentro do conjunto de ações de um Programa de Promoção e Marketing. No que concerne ao seu beneficio, o evento poderá ser de cun ho social ou econômico, traduzindo-se na plena satisfação do clientc, bem como no retorno positivo da interação empreendedor/mercado consumidor. Freqüentemente o papel do evento vem sendo entendido de forma confusa; na maioria dos casos, sua organização e planejamento demonstram caráter de improvisação subjetiva, limitada e externa ao campo de ação mercadológica.

Convencionou-se abordar o público-alvo sem a determinação de ações relacionadas aos preceitos do marketing usual e especificamente ao marketing institucional c de serviços. O evento por vezes é realizado sem o embasamento de políticas de Comunicação; sem o total aferimento da estrutura funcional do empreendedor; conseqüentemente, sem análise das reais potencialidades e oportunidades de que dispõe o empresário (promotor-empreendedor)/instituição nesse momento

Alguns estudiosos desconsideram o marketing convencional ou usual como meio para se alcançar as considerações mercadológicas do marketing institucional ou de serviços. Deve-se lembrar, ainda, que em determinados momentos o evento estará promovendo não só a prestação de serviços, como organizações, idéias, locais e até produtos.

Essa promoção é, portanto, passível de planejamento de marketing com metas especificas que, de forma alguma dispensam suas regras fundamentais em detrimento de considerações empíricas.

Os eventos, se considerados enquanto realizações diversas - congressos, seminários, feiras, lançamentos de produtos etc. - e respeitadas as suas especificidades, exigem tratamento adequado a cada situação sem prejuizo de um estudo mais aprofundado das regras básicas do marketing usual para, somente neste momento, direcionar-se ao objetivo de cada marketing específico, já que se considera o evento como instnunento de promoção e marketing.

O momento de propagação de informações e idéias, lançamentos de produtos ou divulgação de novas paisagens e culturas - 0 evento - precede a pesquisas e experimentos, indicadores econômicos e sociais relevantes que irão orientar a necessidade de metodologia de divulgação e promoção, onde, certamente estará cumprindo o seu papel.

Os eventos não acontecem espontaneamente ou isoladamente. São a conclusão de um exaustivo processo de interpretação do produto, patrimônio ou serviço, sua avaliação mercadológica, a definição deseus canais de distribuição e finalmente seu planejamento de marketing e promoções, onde o evento está inserido como estratégia final

\section{Marketing Turistico e Eventos}

No universo do turismo consideram-se os eventos cm duas fases distintas:

- como atividade promocional da imagem de uma localidade ou empresa e o calendário turístico de um núcleo;

- dentro da ótica do próprio segmento de turismo - turismo de cventos - segmento este que atua diretamente no receptivo à demanda característica dos eventos em geral.

Em ambos os casos, o estudo do processo de planejamento em marketing é fundamental. No caso de turismo se faz necessário, além da preliminar convencional, o estudo da especificidade - o markcting turistico. 
Os profissionais da área de eventos deveriam dominar as técnicas de planejamento em marketing para obter resultados satisfatórios.

\section{Marketing Turistico}

Desde a Revolução Industrial o conceito de tempo livre vem sendo sistematicamente modificado à medida queeste próprio tempo ganha dimensões diferentes. É sabido que o espaço de tempo entre uma jornada de trabalho e outra - tempo livre - principalmente durante os finais de semana, feriados e férias, vem sendo utilizado de diversas formas, entre elas com o ato de viajar.

As pessoas se deslocam das cidades onde moram, em direção aos mais variados locais, em busca da realização de suas necessidades ou desejos. As motivaçõe s que levam o indivíduo a buscar o descanso, o lazer, a aventura etc. são atendidas através da oferta de atrativos naturais, históricos e culturais, mercadorias e serviços que cada localidade quer ou pode oferecer.

A esses municípios anfitriões dá-se o nome de núcleos receptores que, devidamente estruturados, são caracterizados como núcleos turísticos. Os locais de origem dos visitantes são denominados, por sua vez, núcleos emissores. Percebese, portanto, um Sistema de Turismo atuando e envolvendo relações ambientais, sociais, culturais e eminentemente econômicas.

Ao se falar em Turismo, remonta-se a viagens, hotéis, restaurantes, compras - equipamentos e serviços - que envolvem a troca de divisas por estes. Essas relações de troca dimensionamo mercado turístico que, como qualquer outro, sofre variações determinantes ao seu equilíbrio.

O equilibrio mercadológico é alcançado quando a oferta de bens e serviços e satisfatoriamente absorvida pelo mercado consumidor que, por sua vez, e prontamente atendido em sua procura. Os recursos disponiveis para se atingir tal objetivo serão eficazes se devidamente planejados, organizados e controlados, utilizando-se de informações fidedignas advindas de rigorosa investigação. Identifica-se, neste momento, o planejamento de marketing; palavra derivada do inglês "market" cuja tradução é mercado. Esse planejamento irá cumprir sua função na medida em que conseguir manter a freqüência do consumo dos bens e serviços que outros tenham criado ou produzido.

Investigada e definida a necessidade do mercado consumidor ( $a$ demanda) e criados bens e serviços que a satisfaçam ( $a$ oferta), torna-se necessário a criação de oportunidades e possibilidades para que tais produtos sejam conhecidos. A demanda por determinada oferta elegerá seu produto/serviço em meio a concorrência à medida que o tenha conhecido, cxperimentado e aprovado.

O desenvolvimento ininternupto da atividade do Turismo, a expansão de seus produtos, tanto no âmbito nacional como internacional, vêm promovendo uma situação comum a todos os países onde a atual geração de consumidores e crescente demanda justificam a planificação estratégica da atividade descrita que nada mais é do que a ação do marketing turístico. Essa planificação é entendida como o processo sistemático de gerenciamento norteado para atender aos desejos e neces sidades (motivações) do consumidor, reconhecendo-se e avaliando-se as alterações tecnológicas, econômicas e sociais, bem como a análise da concorrência, promoção e comercialização de seus produtos/serviços.

\section{Eventos em Turismo}

Para se cumprir o objetivo de promoção e divulgação de um bem ou serviço - produto turístico - utiliza-se das ferramentas e técnicas de promoção em marketing que respondam à expectativa de satisfação das motivações turísticas e proporcionem retorno que evidenciem novas condições e exigências do próprio mercado. Mais uma vez se faz necessário estabelecer o sistema de informações e controle para se proceder à mensuração da potencialidade real da empresa ou localidade turística, obviamente tendo-se observado, medido e supervisionado o desenvolvimento desses, avaliado seus lucros, nesse caso, então implantar decisões que irão contemplá-los com a adoção de medidas de correção (se necessário) e promoção, de acordo com os resultados da investigação.

Medidas e corrigidas as ações e produtos turísticos de forma a apresentá-los competitivos, seguros e estáveis, a empresa ou localidade define as formas para divulgar seus atrativos dentro dos parâmetros do marketing e delineiam a imagem que irá influenciar o consumo (demanda). Em virtude das características de intangibilidade do produto turístico e das distâncias fisicas entre o mercado receptor (oferta) e o emissor (demanda), tal divulgação e promoção irão transmitir "imagens" por meios de ações dos meios de comunicação.

Influenciando o processo de conhecimento e posterior compra, aparece o evento turístico como instrumento e meio de comunicação, atuando como estratégia de promoção e marketing. O evento está sendoutilizado como um dos instrumentos mais viáveis e de maior sucesso. A implantação das atuais e solisticadas técnicas de promoção e comercialização garantem a divulgação e o implemento de novas tecnologias turísticas.

A sofisticação vem permitindo a organização de programações - eventos que estão motivando e orientando o consumo de determinada localidade - bens serviços - e diminuindo a ociosidade característica da baixa estação; com isso promovendo melhor aproveitamento do produto turistico. Os eventos estão criando oportunidades de viagens, ampliando o consumo, permitindo a estabilidade dos níveis de emprego do setor, promovendo o núcleo receptor e definindo novas estratégias de desenvolvimento e comercialização do produto.

Dentro dessa ótica, a captação de eventos para o núcleo receptor ou os eventos promocionais em núcleos emissores se completam com a elaboração de um calendário em que são registrados as programações dentro de cada núcleo (Festa do Peão de Boiadeiro, festas religiosas, competições culturais e esportivas etc.) ou fora dele (exposições, congressos e feiras promovidos pelo "trade"turístico), que se caracterizam pela promoção, divulgação e 
comercialização desse núcleo ou são partes inerentes aos seus atrativos.

O calendário de eventos é o canal de informação que expressa fatos e costumes diferenciados, difundindo um conhecimento mais profundo de valores atrativos. Os eventos promocionais destacados no Turismo moderno desempenham, através dos centros de convenções, pavilhões de exposições e feiras, pape relevante na economia pela sua função estratégica de reduzir a sazonalidade e aumentar o fluxo turístico nos períodos de baixa estação - promoção. Ambos tornaram-se uma forma de as localidades ou entidades turísticas promoverem suas imagens.

Em busca do reconhecimento definitivo do papel do Turismo no cenário socioeconômico mundial, os eventos turísticos vêm demonstrando sua força na divulgação de seus bens e produtos e na promoção de suas ações, chamando a atenção das autoridades governamentais para o setor, como também vêm abrindo espaços para parcerias e realizações de novos negócios dentro do mercado mundial.

\section{Turismo de Eventos}

Existem vários tipos de cventos que se realizam dentro do universo das mais diversas áreas. São congressos, conferências, cursos, exposições, feiras, shows, simpósios, solenidades etc., que refletem o esforço mercadológico das áreas de ciências médicas, culturais, econômicas, jurídicas, artísticas, esportivas e comerciais ao ingressarem em seus mercados potenciais com novas tecnologias, descobertas científicas e produtos.

A realização desses eventos vem proporcionar ao gnıpo de profissionais de uma mesma área a troca de informações, a atualização de tecnologia, o debate de novas proposições, o lançamento de um novo produto (cultural, histórico, social, industrial, comercial) etc. Ao aproximarem os grupos de interesses, os eventos estão contribuindo para a geração e o fortalecimento das relações sociais, industriais, culturais e comerciais, ao mesmo tempo em que estão gerando fluxos de deslocamento e visitação.

Esse intercâmbio de espaços temporal e físico, acompanhado das atividades relacionadas ao transporte, hotelaria, alimentação e outros provocam o acontecimento turístico. E não só o acontecimento turístico, na medida em que utiliza seus equipamentos e serviços e gera recursos e divisas, como também esses eventos se transformam em atrações fortes o suficiente para conquistarem uma demanda.

Contrastando com a atividade de promoção de eventos turísticos, essa fatia de mercado de promoção e marketing é promovido pelas mais diversas entidades, organizações e empresas, c dinamiza a participação de um número sem-fim de atividades correlatas, conquistando mercado para o turismo de negócios e eventos.

Turismo, mais que outras atividades, é um instnunento de desenvolvimento econômico e social (qualidade de vida) de maior relevância dentro de um universo de serviços e tecnologias avançadas.

O segmento de turismo de eventos é a resposta ao crescimento da necessi- dade da ampliação dos setores de hotelaria, "catering" e transportes frente à expansão de volume dos movimentos de negócios e promocionais desenvolvidos no mix de eventos. O turismo de eventossurge com a finalidade de planejar e organizar o receptivo dessa demanda exclusiva, dando uma imagem característica àquelas localidades cujo potencial de interesse reside no fluxo nacional e internacional de negócios.

Há várias localidades cuja vocação turística relaciona-se aos negócios. Nessas, percebe-se o movimento financeiro substancial e a geração de empregos considerável que justificam a criação de um "pool" de profissionais dedicados à área de eventos e de um outro dedicados à área de turismo receptivo para eventos. A linha demarcatória diferencial entre os dois conceitos - eventos em turismo e turismo de eventos - ainda não é plenamente aceita e continuadamente confundida.

As pessoas que se dedicam à atividade de planejamento e organização de eventos o fazem em qualquer área, inclusive a turística. Os profissionais dedicados à recepção do contingente humano que freqüienta os eventos são os que trafegam nas diretrizes do Turismo, mais especificamente o turismo de eventos. São políticas diversas norteadas para a finalidade comum - o universo do evento.

\section{Consideraçōes Finais}

É oportuno lembrar que no mercado existem duas partes distintas: uma que produz e comercializa o produto ou serviço e outra que os compra e consome. E necessário existir um elo entre as partes que promova o contato e facilite intercâmbio de forma rentável e satisfatória entre as mesmas. Existindo a oferta e a procura (demanda ) desta, existe a necessidade de se tornar público o que se tem para ofertar e ser consumido e, da mesma forma, quem pode e deseja fazê-lo.

O papel determinante da promoção e marketing é o de fazer acontecer esse processo, desde a investigação e análise minuciosa das necessidades da sociedade até a oferta da satisfação de seus desejos, procedendo às mudanças e correções de determinada época.

Como toda ciência convencional pressupõe especificações adequadas a cada momento, o marketing usual norteia o marketing turístico e suas aplicações e abrangência, com o objetivo final de dimensionar um programa promocional que tem no evento sua estratégia.

\section{Bibliografio}

ABRESI/SEBRAE. 1996. A indistria do turismo no Brasil. Perfil \&'k tendèncias. Brasilia: Instituto Brasileiro de Turismo EMBRATUR.

CARNEIRO, Janaina Britto e FONTES, Nena Dantas. 1996. Projeto especial de treinamentos - P.E.T 2. Planejamento

e organização de eventos. São Paulo: Dantas Britto Projetos em Turismo e Eventos
DI-BELLA, Manuel Gurria. 1991. Introducción al Turismo. México: Editorial Trillas.

GIÁCOMO, Cristina. 1993. Tudo acaba em festa Evento, lider de opinião, motivação e priblico. São Paulo: Editorial 
KOTLER, Philip.1993. Principios de marketing. Rio de Janeiro: Editora Prentice-Hall do Brasil Ltda

MACHIN, Carmem Altés. 1993. Marketing y Turismo. Madrid: Editorial Síntesis.

SANTOS, Antōnio Oliveira. 1993. Organização de ev'entos. Rio de Janeiro: Centro Técnico-Pedagógico Léa Viveiros de Castro.

SCHLUTER, Regina G. e WINTER, Gabriel.1993. ElFenomeno Tunistico. Argentina: Fundación Universidad a Distancia "Hemandarias".

TABARES, Fábio Cardenas. 1991. Mercadotecnia y Productividad. México: Editorial Trillas.

WAHAB, Salah-Eldin Abdel. 1991. Introdução à Administração do Turismo (alguns aspectos estruturais eoperacionais do turismo internacional). Såo Paulo: Editora Pioneira.

Recebido em $16 / 1 / 97$

Aprovado em 10/5/97 